\title{
Research on MOOC's Teaching Method About the Category of Innovation and Entrepreneurship Courses
}

\author{
Ling Huang \\ School of Finance \\ Fuzhou University of International Studies and Trade \\ Fuzhou, China
}

\author{
Longyao Lan \\ School of Finance \\ Fuzhou University of International Studies and Trade \\ Fuzhou, China
}

\begin{abstract}
With the overall disposition in informationized education and the national "Internet plus" strategy, "Widespread Entrepreneurship and Innovation" is supported by more solid technology. The MOOC's teaching method of innovation and entrepreneurship courses is just adapted for the current visual teaching method which is popularized all over the society, realizing the breakthrough in four aspects: the limit in space and time, the bondage of uniqueness about knowledge system, the bottleneck in the lack of teaching resources, and one sidedness of performance evaluation. It truly realizes the free choice of learning space and time, diversified support for curriculum contents on the multi-level, re-integration and re-optimization for the teaching resources, and is more comprehensive in the performance evaluation method.
\end{abstract}

Keywords- "Internet plus"; the category of innovation and entrepreneurship courses; MOOC's teaching method; modularization; DIY reconstruction

\section{INTRODUCTION}

Innovation and entrepreneurship have become the driving force of the country's progress. More and more innovation and entrepreneurship courses have been implanted into the university curriculum system, which enables students to receive theoretical knowledge of higher education, while imperceptibly stimulating the awareness of innovation and entrepreneurship. At the same time, another revolution in information technology — the "Internet + " revolution has also undergone great changes in the field of education. The endless MOOC courses and mobile interactive software enrich teaching resources, make classroom resources diversified, and even make online and offline hybrid teaching possible, and the learning process becomes an effective and gradual process. The MOOC teaching method of innovation and entrepreneurship courses combines the two major national educational backgrounds and changes. It not only enables college students to break the time and space restrictions, and freely choose the time and space for learning, but also enables social people to integrate into online learning platform anytime and anywhere.

\section{Problem Statement}

At the beginning of 2010, education informatization has been regarded as an endogenous variable of education system reform. An important feature of education informatization is to spread teaching resources fairly with the Internet as the carrier. In the same year, the integration of higher education and innovation and entrepreneurship education was also put on the agenda. The Ministry of education pointed out "Developing innovation and entrepreneurship education in Colleges and Universities...Employment driven by entrepreneurship" in "The Opinions on Vigorously Promoting Innovation and Entrepreneurship Education in Colleges and Universities and the Work of Independent Entrepreneurship of College Students". At the 2014 Summer Davos forum, Premier Li Keqiang proposed "mass entrepreneurship and innovation". Therefore, the innovation and entrepreneurship courses are not only an independent discipline, but also embedded in the curriculum system of higher education in various forms, and become the incubator of various innovative projects by promoting learning through competition.

However, the integration of the two kinds of Education Strategies - "education informatization" and "innovation and entrepreneurship education" faces many challenges. First, the level of knowledge dissemination and testing system of traditional innovation and entrepreneurship courses is weak. Teachers mainly teach and slide show, and teaching resources are mainly text, video and pictures, which can't realize the deep understanding and exploration of knowledge; students can only test the consolidation of knowledge points through theoretical exercises; teachers and students have less interaction, and the knowledge system has almost no extension, which can't realize the function of multi-level supporting knowledge system.

Second, the space and geographical scope are limited Most colleges and universities, limited by the number of students and the number of classrooms, can only arrange courses in each department or the academic affairs office. Students can attend classes in the corresponding classrooms on time and according to the location, which cannot achieve the students' independent choice of courses (except for public elective courses), nor improve their practical ability (except for experimental courses). Even if the innovation and entrepreneurship courses have high requirements for students' practical ability, they passively accept knowledge in the classroom. In the classroom, they spread knowledge through a series of pure theoretical and written teaching 
methods: teaching materials, magic slides and blackboard writing, which are very incompatible with the objectives and ability demands of innovation and entrepreneurship courses.

Third, the theory of teaching mode is too long. The traditional curriculum system focuses on the teaching of theoretical knowledge. Teaching materials are used to disseminate knowledge, but the teaching materials are almost not updated. Even if the teaching materials are updated, there is a lag from "collecting materials, updating teaching materials and disseminating resources", which leads to students' inability to master the latest project operation in the case of rapid changes in entrepreneurial projects. In the age of Internet, students can get these theories and definitions from the Internet.

Fourthly, there is a lack of teaching resources. From the perspective of teachers, most college teachers are scholars who accept pure theoretical education. They have neither entrepreneurial experience nor enterprise work experience. Even if they have work experience, they have nothing to do with the field of innovation and entrepreneurship, so they are not suitable to be teaching teachers of innovation and entrepreneurship courses. Now, the common situation is that counselors act as innovation and entrepreneurship courses. The instructors of new entrepreneurship course, of course, do not have the experience and background of innovation and entrepreneurship. In terms of teaching materials, it mainly relies on teaching materials, videos and homework to spread knowledge.

To sum up, for innovation and entrepreneurship courses, building a curriculum model with diversified knowledge system, novel teaching methods and strong practicality has become a problem that colleges and universities need to solve under the background of high embeddedness of innovation and entrepreneurship courses.

\section{LITERATURE REVIEW}

\section{A. The Background of Educational Informatization and the Background of "Internet Plus" Development Strategy}

The Ministry of education, in line with the major strategic tasks such as "Internet +", big data and new generation of artificial intelligence, issued some regulations to support modern education, including the 2 action plan of education informatization (Hereinafter referred to as the "2.0 Plan"), and the outline of the national medium and long term educational reform and development plan (2010 to 2020). The 2.0 plan points out that educational informatization has the unique advantages of breaking through the limitation of time and space, rapid replication and dissemination, and rich presentation means, and will become an effective means to promote education equity and improve education quality.

The key link in the process of educational informatization is to build a big platform of "Internet + education", which transforms from educational special resources to educational resources, and from integrated application to innovative development (Zhong Shaochun, Tang Yewei, 2018).[3] "The phrase "Internet +" was first put forward by Premier Li Keqiang in the three session of the twelve National People's Congress in March 5, 2015 (Zhao Zhuqing, 2015). [4] In July 4, 2015, Premier Li Keqiang signed the "Guiding Opinions on Actively Promoting The 'Internet + ' Action" (Hereinafter referred to as "Guiding Opinions"). In the Guiding Opinions, "Internet + " is a key action plan. In this regard, "Internet + " will become the strategic orientation of all walks of life in China in the future. [5] The so-called "Internet +" is the "Internet +", which refers to the use of the Internet platform, information and communication technology to integrate the Internet and other industries including traditional industries, so as to create a new ecosystem in the new field (Suhe, 2015). [6] "Internet +"is a new form of knowledge dissemination, promoting the innovation of knowledge society, changing people's working mode and education mode, so as to form a more extensive new normal of education with Internet as catalyst; retail industry and education and training industry have realized the geometric multiple growth of the number of audiences through the operation mode with Internet as carrier in recent years.

\section{B. Current Situation of Innovation and Entrepreneurship Education}

In the year of 2010 "Opinions of the Ministry of Education on Vigorously Promoting Innovation and Entrepreneurship Education in Colleges and Universities and Independent Entrepreneurship of College Students", it is the first time to emphasize that innovation and entrepreneurship education should be introduced into higher education in the form of a document.[7] With the continuous development of technology and the continuous transformation of consumption mode, production mode and life style, the connotation of "innovation and entrepreneurship" changes with each passing day. Today's entrepreneurial technology may be out of date tomorrow, so innovation and entrepreneurship education focuses on the cultivation of innovation spirit, innovation idea and innovation thinking (Dong Yunfei, Zheng Libo, 2014).[8]

Zhang he (2014) proposed the method of enterprise management: "Three Standards In One", that is, quality (QMS), environment (EMS) and occupational health and safety (OHSAS) are introduced into the curriculum system of innovation and entrepreneurship education to ensure the stability of operation mechanism and standardized management; meanwhile, the "Three In One" model is adopted to build a community of government, enterprises and schools [9]. However, the practice of innovation and entrepreneurship needs huge social resources and enterprise posts to digest, "students entering the enterprise - difficult" has become the consensus of school enterprise cooperation. But the sudden change in technology makes it possible for enterprises to enter schools. With the continuous development of cloud computing technology and big data technology, innovation and entrepreneurship education can integrate these two technologies into Virtual Practice Teaching Platform (VPTP), integrate the real process of enterprises into innovation and entrepreneurship education, so as to improve students' practical ability, even reach the 


\section{THE ESTABLISHMENT OF MOOC TEACHING SySteM FOR INNOVATION AND ENTREPRENEURSHIP COURSES}

The biggest advantage of MOOCS is the reorganization and fragmentation of the curriculum system. Each knowledge point can be an independent module, which is supported by rich teaching resources. The entrepreneurial process involves all kinds of skills, and the key links include: entrepreneurial project selection, entrepreneurial project skills learning, business plan writing, enterprise establishment and registration, financing plan, Internet finance, marketing strategy, market sales forecast, budget statement preparation, which can be DIY based on the teaching resources of each school Restructuring, the key link in the process of entrepreneurship modular teaching.

\section{A. Re-integration of Teaching Resources}

The re-integration of teaching resources can break the discipline barriers and integrate high-quality teaching resources. Because the whole entrepreneurial process involves product knowledge, marketing knowledge, financial knowledge, financial knowledge, statistical knowledge, etc., relying on a certain teacher, or a teaching unit's faculty, are not enough to support the teaching of innovative entrepreneurship courses. The so-called technology industry has its own specialty. The advantage of modularization of curriculum system lies in that this course can be jointly built by different specialties, departments and colleges, and the best teaching materials and evaluation methods can be selected by selecting higher quality teachers. The reintegration of resources enables teachers in charge of each module to refine the teaching resources.

\section{B. Diversified Teaching Methods}

The characteristics of MOOC teaching methods are the diversity of teaching resources and teaching methods. The support of knowledge system is interpenetrated from point to surface. Each knowledge point uses video, case, test question, hands-on practice and other ways to interpenetrate knowledge network in multiple levels. Each video is a knowledge point, 5-10 minutes, which can be taken by the teachers themselves or intercepted in the network. Each video is equipped with cases, test questions and practical experiments to support this knowledge point. Due to the refinement of MOOC courses, students spend much less time online than in traditional classroom, so offline teaching can accommodate more time to organize students' independent learning, and can use group discussion, flipped classroom and SPOC teaching methods. This way is more consistent with the teaching objectives of innovation and entrepreneurship courses, focusing on the cultivation of students' entrepreneurial practice ability, so that students can mobilize a variety of perceptions to understand the key links in the process of innovation and entrepreneurship.

\section{Improvement of Effectiveness Evaluation Method}

The teaching process of innovation and entrepreneurship courses is divided into two parts: online and offline. The online performance evaluation method mainly consists of five aspects: video viewing, homework, quiz, discussion and 
[5] The State Council. The State Council's Guiding Opinions On Actively Promoting The "Internet +" Action [Z]. NDRC [2015]40, 2015-07-04

work uploading. According to their importance, teachers of each module can evaluate their own scores, which are calculated by the platform side system, which is more accurate and objective. Because the process of online learning is prior to offline learning, which requires a high level of autonomous learning, students need to collect a wide range of information to complete the assessment and discussion after class. In offline teaching, group interactive $\mathrm{Q}$ \& A, discussion, quiz and business plan writing can be carried out alternately. Each link also needs to be given weight according to the importance and students' performance. It can reflect the students' learning situation more comprehensively and fairly through the diversified and multi-level effective and stable way.

\section{CONCLUSION}

The popularization of innovation and entrepreneurship courses is matched with the national innovation driven strategic goal. Its ultimate goal is to cultivate students' innovative thinking and cultivate innovative talents. The promotion of innovation and entrepreneurship courses is conducive to the full exercise of students' self and the stimulation of entrepreneurship passion. At the same time, we should realize that the "innovation training plan for college students" is a systematic project, which needs to combine the Internet technology, hardware facilities, curriculum design, teacher integration, innovation of entrepreneurship projects and other elements. Based on MOOC, a popular teaching resource, as the main teaching method, this paper firstly reorganizes the teaching content in DIY mode to modularize the curriculum system; secondly, it reorganizes the teaching resources, including the integration of teachers and teaching materials; the teaching methods should be diversified: test, flipped teaching, discussion teaching, performance teaching and case teaching; The way of performance evaluation is multi-dimensional. The focus of innovation and entrepreneurship courses is to embed the thinking of innovation and entrepreneurship into students. Through the re-creation and design of courses, students are given the ability to write business plans, establish and register enterprises, design business models, raise funds, market marketing and budget funds.

\section{REFERENCES}

[1] The Ministry Of Education. Opinions Of The Ministry Of Education On Vigorously Promoting Innovation And Entrepreneurship Education In Colleges And Universities And Independent Entrepreneurship Of College Students [Z]. Education Office [2010] No. 3, 2010-5-13

[2] The Ministry Of Education. Circular of the Ministry of education on printing and distributing the action plan of educational informatization 2.0 [Z]. Education and technology [2018] 6

[3] Zhong Shaochun, Tang Yiwei. Research on the direction and path of educational innovation in the era of artificial intelligence [J]. Research on audio visual education, 2018 (10): 15-20

[4] Zhao Zhuqing, academics are hot: what is the concept of "Internet +" proposed by Li Keqiang? [EB/OL] People's website, http://scitech.people.com.cn/n/2015/0305/c1007-26644489.html (March 5, 2015)
[6] Su He. Ma Huateng Talk About "Internet +" [N]. China Youth Daily, T02-1503-05

[7] Dong Yunfei, Zheng Libo. Strategic Thinking On Cultivating College Students' Innovation And Entrepreneurship Ability [J]. Heilongjiang Social Science, 2014 (5): 157-159

[8] Zhang He. Research On Innovation And Entrepreneurship Education In Colleges And Universities: Mechanism, Path And Mode [J]. Journal of the State Education Administration College, 2014 (10): 2832

[9] Yan Yuping. Research On The Cultivation Mode of Innovation And Entrepreneurship Ability of Business Students Based On VPTP [J]. Research On Audio Visual Education, 2014 (10): 48-52

[10] Salmon G, Siemen G, Ally M. A Learning Theory for the Digital Age [J]. Instructional Technology and Distance Education , 2004- 2(1) :19

[11] Zhao Lei. Research On The Motivation And Path Of Innovation And Diffusion Of MOOC In Universities [D]. Dalian University Of

[12] INGE DE WAARD, APOSTOLOS KOUTROPOULOS, etc. He Fugang, Ma Dongming, Sun Haimin (Translation). Exploring The Application of MOOC Teaching Method In Mlearning [J]. China Distance Education, 2012 (3) Choice of Adult Higher Education [J]. China Adult Education, 2017 (24):23-26

[14] Xu Yang. Cultivation And Application of Hybrid Learning, Innovation And Entrepreneurship In The Context Of MOOC [J]. Guangdong Sericulture, 2018 (11): 147-148

[15] Lin Xuezhi, Su Kaihui. Ideas And Strategies For The Construction of Innovation And Entrepreneurship MOOC Platform In Colleges And Universities [J]. Journal Of Zhejiang Shuren University (NATURAL SCIENCE EDITION), 2016 (1) Technology, 2017

[13] Tang Weizhi, Pang Yan, Xue Xiya. MOOC And The Development 